\title{
ESTABILIDADE AERÓBIA DE CANA-DE-AÇÚCAR IN NATURA HIDROLISADA COM CAL VIRGEM
}

\author{
Carlos Henrique Silveira Rabelo ${ }^{1}$, Adauton Vilela de Rezende ${ }^{2}$, Flávio Henrique Silveira Rabelo ${ }^{3}$, \\ Denismar Alves Nogueira ${ }^{4}$, Rafael Ferreira Elias ${ }^{1}$, Danni CÉSAR Nogueira AchCAR de Faria JúnioR ${ }^{3}$ \\ 1 - Graduando em Zootecnia na Universidade José do Rosário Vellano (UNIFENAS) - carlos.zoo@hotmail.com \\ 2 - Professor da Universidade José do Rosário Vellano (UNIFENAS-MG) \\ 3 - Graduando em Agronomia da UNIFENAS \\ 4 - Professor da Universidade Federal de Alfenas (UNIFAL-MG)
}

Objetivou-se com esta pesquisa avaliar o efeito da
inclusão de cal virgem sobre a estabilidade aeróbia da
cana-de-açúcar in natura. O trabalho foi conduzido na
Faculdade de Zootecnia da UNIFENAS, sob
delineamento experimental inteiramente casualizado, em
esquema fatorial 4 x 5 , avaliando-se quatro doses de cal
$(0,0 ; 0,5 ; 1,0$ e $2,0 \%$ em relação à matéria natural) e
cinco tempos de exposição aeróbia ( $0,12,24,48$ e 72
horas após o momento da hidrólise), com quatro
repetições. A inclusão do aditivo na cana-de-açúcar in
natura provocou aumento no teor de matéria seca e nos
valores de pH. Porém, os valores de pH diminuíram com

o decorrer do tempo, em função da ação de microrganismos. Em relação à temperatura, esta aumentou quando se adicionou $1,0 \%$ de cal à cana-deaçúcar; no entanto, o menor valor referente ao acúmulo da temperatura durante as aferições foi obtido com a utilização de $2,0 \%$ de cal, e da mesma forma, a menor taxa de aquecimento foi obtida para este mesmo tratamento. De certa forma, a utilização de $2,0 \%$ de cal virgem aumentou a estabilidade aeróbia da cana-deaçúcar, porém, todos os tratamentos apresentaram instabilidade aeróbia poucas horas após o momento da mistura entre cal e cana-de-açúcar.

PALAVRAS-CHAVE: alcalinização; óxido de cálcio; $\mathrm{pH}$; temperatura.

ABSTRACT

\section{AEROBIC STABILITY OF IN NATURA SUGARCANE HYDROLYZED WITH CALCIUM OXIDE}

It was aimed through this research work to evaluate the effect of including calcium oxide over the aerobic stability of in natura sugar cane. The wok was conducted in the Animal Science College of UNIFENAS in a completely randomized design (CRD) in a 4 × 5 factorial scheme, evaluating four doses of calcium oxide $(0.0 ; 0.5$;
1.0 and $2.0 \%$ relative to natural matter) and five times of aerobic exposition $(0,12,24,48$ and 72 hours after the moment of hydrolysis) with four replicates. The inclusion of the additive in natura sugar cane increased dry matter and $\mathrm{pH}$ rates. But the $\mathrm{pH}$ values decreased over time in relation to temperature due to microorganism activity. 
Temperature increased when $1.0 \%$ of calcium oxide was added to the sugarcane; nevertheless, the lowest value concerning the accumulation of temperature during the measurements was obtained with the use of $2 \%$ of calcium oxide and in the same manner, the lowest rate of heating was obtained for this same treatment. In a certain manner, the use of $2 \%$ of calcium oxide increased the aerobic stability of sugarcane, but all the treatments showed aerobic instability few hours after the moment of mixing between calcium oxide and sugarcane.

KEY-WORDS: alkalinization; calcium oxide; $\mathrm{pH}$; temperature.

\section{INTRODUÇÃO}

Durante décadas a cana-de-açúcar vem sendo estudada como volumoso na alimentação dos ruminantes, em virtude da sua alta produtividade aliada ao melhor valor nutritivo apresentado na época de seca no país, favorecendo sua utilização na alimentação de várias categorias animais, que apresentam bom desempenho na produção de carne e leite quando alimentados com este volumoso.

PEDROSO et al. (2007) constataram que o valor nutritivo da cana-de-açúcar, quando ensilada, sofre depreciação com o processo de fermentação, resultando em produtos de baixa qualidade. Por isso, o uso da cana-de-açúcar em seu estado in natura vem sendo cada vez mais utilizado, pois apresenta melhor valor nutritivo em relação à silagem, sendo mais indicada para o fornecimento aos animais. Segundo NUSSIO et al. (2009), o fornecimento da cana-de-açúcar na forma in natura tem possibilitado alternativas de manejo com base na utilização de agentes hidrolíticos imediatamente após a colheita da forragem no campo e posterior armazenamento desse material tratado em ambiente protegido.

De acordo com EZEQUIEL et al. (2005), a utilização do tratamento químico de volumosos é bastante antiga, sendo que a utilização de substâncias alcalinizantes é realizada no intuito de melhorar a digestibilidade e o consumo de alimentos fibrosos, sempre visando melhoria no valor nutricional dos mesmos, como volumosos para ruminantes. A melhoria no valor nutritivo se dá pelo rompimento das frações da parede celular por meio da hidrólise alcalina (KLOPFENSTEIN, 1980), e aumento da estabilidade aeróbia da cana-de-açúcar, potencializando a produção animal em virtude dos microrganismos ruminais aproveitarem melhor a energia contida nas células do alimento (OLIVEIRA et al., 2008a).

Segundo OLIVEIRA et al. (2008a); OLIVEIRA et al. (2008b), atualmente vem sendo divulgada a utilização da cal virgem e cal hidratada no trata- mento da cana-de-açúcar, objetivando aumentar a estabilidade aeróbia e melhorar o aproveitamento das fibras pelos ruminantes, devido à sua expansão pelo efeito da adição deste álcali. Segundo GREENHILL (1964), a atividade de água corresponde ao percentual de água livre disponível ao crescimento de microrganismos e, desta forma, a aplicação de materiais com alto teor de matéria seca reduz a atividade de água na forragem (BALSALOBRE et al., 2001), dificultando o desenvolvimento de microrganismos espoliadores e por consequência diminui a produção de calor ao longo do período de exposição aeróbia.

Buscando conhecer as alterações decorrentes da hidrólise, RIBEIRO et al. (2009) trabalharam com doses crescentes de óxido de cálcio (cal virgem) em cana-de-açúcar tratada em montes e observaram que a utilização do aditivo apresentou efeito benéfico para as variáveis de estabilidade aeróbia, reduzindo o aquecimento da massa e os picos de temperatura.

No entanto, existem poucos trabalhos disponíveis na literatura que avaliam a estabilidade aeróbia de cana-de-açúcar in natura, e os resultados disponíveis apontam para a necessidade de novas pesquisas por serem muitas vezes inconstantes. Desta forma, objetivou-se com esta pesquisa avaliar o efeito da inclusão de cal virgem sobre a estabilidade aeróbia da cana-de-açúcar in natura.

\section{MATERIAL E MÉTODOS}

O experimento foi conduzido em setembro de 2007 na Faculdade de Zootecnia da Universidade José do Rosário Vellano (UNIFENAS), campus de Alfenas (MG), no setor de Forragicultura. O cultivar utilizado foi SP81-3250 fornecido pela Usina Monte Alegre, localizada no município de Monte Belo (MG).

O corte da cana-de-açúcar foi realizado em setembro de 2007 de forma manual, procedendo-se 
o corte a $10 \mathrm{~cm}$ da superfície do solo, quando as plantas estavam com aproximadamente 12 meses de crescimento vegetativo. $\mathrm{O}$ valor do grau Brix da forrageira foi determinado utilizando-se um refratômetro de campo (marca Tokyo ${ }^{\circledR}$ modelo 032), indicando valor médio de $20^{\circ}$.

Após o corte, a cana-de-açúcar foi levada para o setor de Forragicultura da UNIFENAS para moagem, procedendo-se a desintegração em picadeira estacionária, com intenção de obter tamanhos de partículas entre 1,0 e 2,0 cm. Em seguida, foram confeccionados os tratamentos, sendo a cana-deaçúcar imediatamente tratada com óxido de cálcio (cal virgem) a seco, nas proporções 0,$0 ; 0,5 ; 1,0 \mathrm{e}$ $2,0 \mathrm{~kg}$ de cal para cada $100 \mathrm{~kg}$ de cana (massa verde), buscando-se intensa homogeneização. A massa que não recebeu cal virgem $(0,0 \mathrm{~kg})$ permaneceu no estado in natura, para utilização como parâmetro na avaliação da estabilidade aeróbia. De acordo com análise realizada no Laboratório de Análises de Alimentos da UNIFENAS, a cal microprocessada apresentava as seguintes composições: teor máximo de óxido de cálcio $(\mathrm{CaO})$ de $64,0 \%$; teor mínimo de óxido de magnésio $(\mathrm{MgO})$ de 1,5\%; e teor máximo de água de 1,0\%, com granulometria de 100 mesh. $\mathrm{O}$ experimento foi conduzido em galpão coberto.

Após a mistura, foram confeccionados montes de $5 \mathrm{~kg}$ de cana-de-açúcar, mantendo-se as proporções da mistura, que foram postos em baldes com capacidade para $20 \mathrm{~L}$ sem compactação, a fim de facilitar a penetração de ar na massa.

As temperaturas foram aferidas com uso de um termômetro digital, inserido a uma profundidade de $10 \mathrm{~cm}$ no centro da massa. As medições no primeiro dia foram tomadas logo no momento da mistura da cal à cana (23:00 horas), e após 3, 6, 12 e 24 horas. No segundo e terceiro dias a temperatura foi tomada somente uma vez (23:00 horas), pois geralmente as maiores alterações de $\mathrm{pH}$ e temperatura para cana in natura ocorrem logo no primeiro dia, dentro de poucas horas. E por ocasião da análise estatística foram considerados os resultados colhidos somente os tempos $0,12,24,48$ e 72 horas após a mistura. A temperatura média durante os três dias de condução experimental foi de $23,5^{\circ} \mathrm{C}$, enquanto que durante a noite a média foi de $17,1^{\circ} \mathrm{C}$, já a umidade relativa (UR) foi de 77,8 e 51,4\% para a noite e dia, respectivamente. $\mathrm{O} \mathrm{pH}$ foi determinado seguindo as metodologias descritas por SILVA \& QUEIROZ (2002), retirando-se aproximadamente $15 \mathrm{~g}$ da mas- sa para essa análise.

As amostras colhidas nos diferentes tempos para determinação da matéria seca (MS) foram acondicionadas em sacos plásticos, previamente identificados e armazenadas em freezer a $-10^{\circ} \mathrm{C}$, para posteriormente serem analisadas. Durante o processamento das amostras, essas foram secas em estufa de circulação forçada à $65^{\circ} \mathrm{C}$ por 72 horas, conforme SILVA (1981) e, posteriormente, moídas em moinhos tipo Wiley provido de perfurações nas peneiras de $1 \mathrm{~mm}$. O teor de MS da amostra moída foi determinado em estufa a $105^{\circ} \mathrm{C}$, seguindo as metodologias da ASSOCIATION OF OFFICIAL ANALYTICAL CHEMISTS (1970).

Os parâmetros para avaliação da instabilidade aeróbia constituíram-se no aumento em $2^{\circ} \mathrm{C}$ da temperatura da cana-de-açúcar in natura em relação ao ambiente conforme descrito por RANJIT \& KUNG JR. (2000), número de horas para elevação da temperatura das massas em $2^{\circ} \mathrm{C}$ em relação à temperatura ambiente, número de horas para atingir a temperatura máxima, temperatura máxima e soma das médias diárias de temperatura nas massas nos diferentes tempos de coleta, conforme proposto por SIQUEIRA et al. (2005). Também foi calculada a taxa de elevação de temperatura $\left(\mathrm{em}^{\circ} \mathrm{C} / \mathrm{h}\right)$, usando o maior valor observado para temperatura $\left({ }^{\circ} \mathrm{C}\right)$ dividida pelo tempo (em horas) necessário para alcançar esse valor (RUPPEL et al., 1995). Conforme CHERNEY \& CHERNEY (2003), o pH representa um bom indicador da qualidade dos alimentos, e por isso, também foi utilizado como parâmetro na avaliação da estabilidade aeróbia da cana-de-açúcar in natura.

O delineamento experimental utilizado foi o inteiramente casualizado, em esquema fatorial $4 \times 5$, em que se avaliaram quatro doses de cal $(0,0 ; 0,5$; 1,0 e $2,0 \%$ em relação à matéria natural) e cinco tempos de repouso $(0,12,24,48$ e 72 horas após o momento da hidrólise), com quatro repetições. Os dados obtidos foram submetidos à análise de regressão a 5\% de significância por meio do programa estatístico SISVAR ${ }^{\circledR}$ (FERREIRA, 2008), com posterior ajuste de equações.

\section{RESULTADOS E DISCUSSÃO}

O teor de MS da cana-de-açúcar aumentou linearmente $(\mathrm{P}<0,05)$ com a inclusão da cal virgem $\mathrm{e}$, de acordo com a equação $\mathrm{Y}=34,509+0,834 \times\left(\mathrm{r}^{2}=\right.$ 
$87,69 \%$ ), para cada $1,0 \%$ de cal adicionada à massa, houve acréscimo de 0,83 unidades percentuais. Desta forma, os teores de MS verificados para as doses de cal 0,$5 ; 1,0$ e $2,0 \%$ foram respectivamente 34,92 ; 35,34 e $36,17 \%$, e a cana-de-açúcar in natura apresentou $34,50 \%$. O acréscimo observado para essa variável ocorreu em virtude da cal virgem utilizada no experimento ter apresentado $99,0 \%$ de $\mathrm{MS}$, promovendo acréscimos nos teores de MS da cana-deaçúcar, e consequentemente, decréscimo na quantidade de água livre do alimento. Segundo GREENHILL (1964), a atividade de água corresponde ao percentual de água livre disponível ao crescimento de microrganismos e, de acordo com MCDONALD et al. (1991) e BALSALOBRE et al. (2001), a redução da atividade de água, em decorrência do aumento da pressão osmótica, ocorre em materiais que possuem acréscimo nos teores de MS, o que dificulta a atuação de microrganismos e consequente deterioração do alimento.
Houve acréscimo de 0,06 pontos percentuais no teor de $\mathrm{MS}\left(\mathrm{Y}=33,230+0,064 \mathrm{x} ; \mathrm{r}^{2}=76,75 \%\right)$ da cana-de-açúcar para cada hora de repouso $(\mathrm{P}<0,01)$, observando-se teores de MS após 12, 24, 48 e 72 horas do momento da mistura "cana-cal" respectivamente, de 34,00;34,77; 36,32 e 37,86\%. Esse resultado se deve à desidratação natural que o material sofre, pois após o corte da cana-de-açúcar, a planta ainda está em processo de respiração e com intenso metabolismo, o que pode levar ao aumento da temperatura e, por conseguinte, promover perda de água por evaporação.

Verificou-se interação entre dose de cal e tempo de repouso para o teor de $\mathrm{MS}(\mathrm{P}<0,05)$. Procedendo-se ao desdobramento, foi notado que independente da dose utilizada, os teores de MS aumentaram com o decorrer das horas, e os maiores teores foram obtidos nas massas de cana-de-açúcar tratadas com maiores doses de cal (Figura 1).

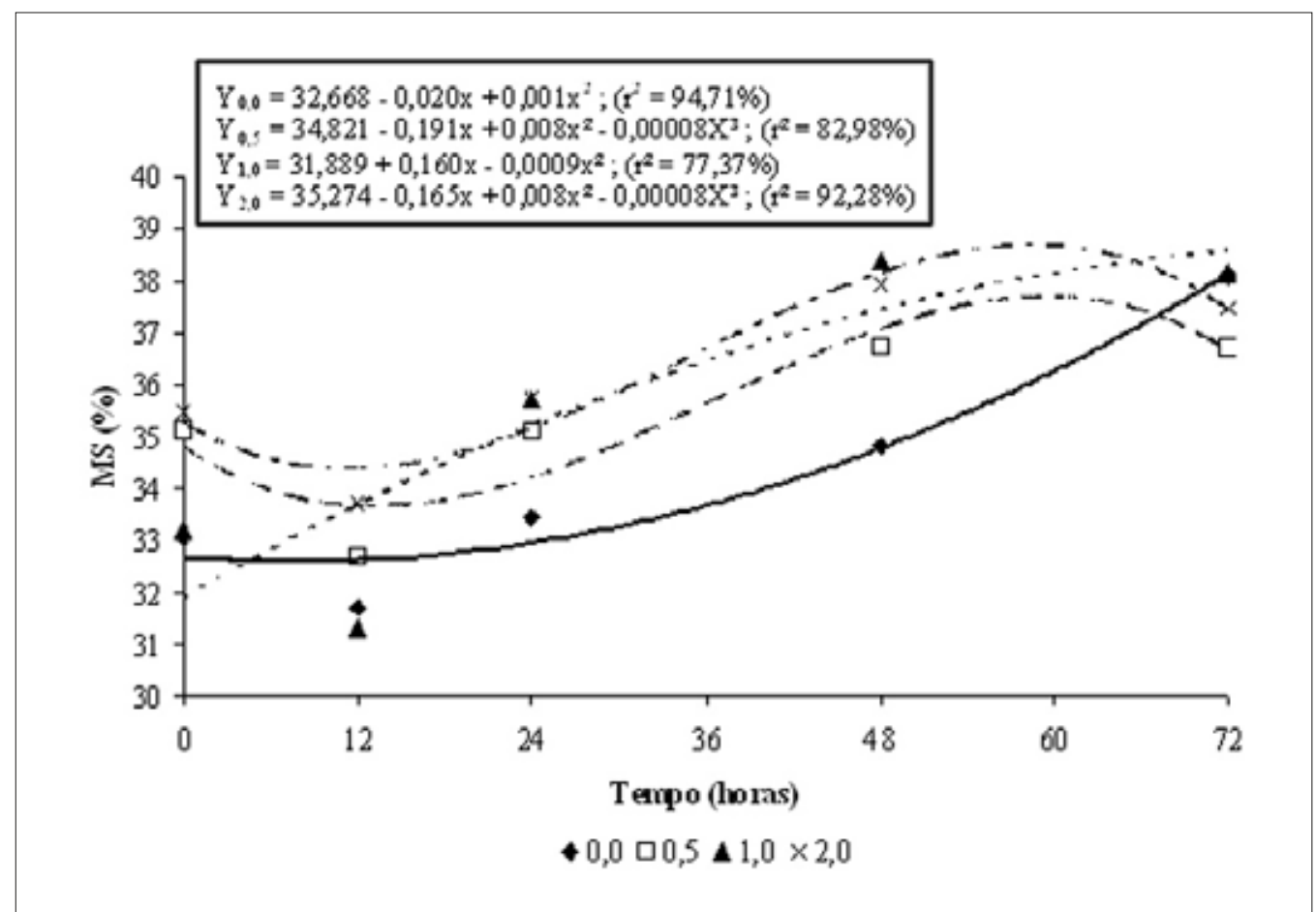

Figura 1 - Desdobramento da interação entre dose de cal virgem e tempo de repouso para o teor de MS.

O acréscimo no teor de MS é um fator que pode aumentar a estabilidade aeróbia da cana-deaçúcar in natura, pois microrganismos necessitam de um ambiente úmido que favoreça seu desenvolvimento, e a adição de cal promove aumento no teor de MS e, por conseguinte, queda no teor de umidade do alimento, o que pode causar uma barreira à repro- dução dos mesmos. OLIVEIRA et al. (2008b) observaram aumento de 0,83 e 0,58 pontos percentuais no teor de MS da cana-de-açúcar com a adição de 0,5 e $1,0 \%$ de cal hidratada (óxido de cálcio $=87,3 \%$ ), respectivamente. AMARAL et al. (2009) encontraram valores de MS da ordem de 30,60;32,20 e $37,50 \%$ para a cana-de-açúcar in natura no primeiro 
dia do ensaio de estabilidade aeróbia, e após cinco e dez dias do início do experimento, respectivamente.

$\mathrm{O} \mathrm{pH}$ aumentou por meio do processamento com cal virgem $(\mathrm{P}<0,01)$, e para cada $1,0 \%$ de cal adicionada à cana-de-açúcar, houve acréscimo de 1,70 unidades $\left(\mathrm{Y}=4,454+1,708 \mathrm{x} ; \mathrm{r}^{2}=98,33 \%\right)$. Esse resultado está intimamente associado à concentração de óxido de cálcio presente no aditivo e a dose utilizada na aplicação e, o acréscimo do $\mathrm{pH}$ é fator preponderante para que ocorra adequado processo hidrolítico. Esses resultados corroboram outras pesquisas avaliando forragens (BALIEIRO NETO et al., 2009; OLIVEIRA et al., 2008a; OLIVEIRA et al., 2008b) que trabalharam com concentrações de óxido de cálcio variáveis, modos de aplicação diferentes e tempos diferentes ao deste trabalho. No entanto, este resultado confirma a hipótese de aumento nos valores de $\mathrm{pH}$ quando se utilizam aditivos alcalinos.

Com o decorrer das horas, notou-se queda nos valores de $\mathrm{pH}(\mathrm{P}<0,01)$, e de acordo com a equação de regressão $\mathrm{Y}=8,038-0,066 \mathrm{x}\left(\mathrm{r}^{2}=70,10 \%\right)$, para cada hora de exposição aeróbia em que as massas de cana-de-açúcar foram submetidas, houve queda em 0,06 unidades. Apesar de esse fato ocorrer naturalmente, ele não é interessante, pois a queda do $\mathrm{pH}$ ocorre pela ação de microrganismos, que consomem carboidratos solúveis ocasionando a acidificação da massa e, desta forma, a estabilidade aeróbia da canade-açúcar diminui.

Procedendo-se ao desdobramento da interação dose de cal virgem e tempo de repouso $(\mathrm{P}<0,01)$ para valores de $\mathrm{pH}$, notaram-se maiores valores e maior variação no decorrer das horas (6,51 unidades) com adição de 2,0\% de cal. A cana-de-açúcar que permaneceu no estado in natura apresentou menor variação no $\mathrm{pH}$ (2,43 unidades), o que era esperado, pois a cana-de-açúcar in natura por si não apresenta valores de $\mathrm{pH}$ elevados. No entanto, quando se adiciona cal virgem, o $\mathrm{pH}$ se eleva substancialmente, e com o decorrer das horas, a acidificação provoca maiores alterações nessa variável. OLIVEIRA et al. (2008a) verificaram que a aplicação da cal hidratada (72,50\% de óxido de cálcio) resultou em valores mais elevados de $\mathrm{pH}$ e, ainda, que a cana-de-açúcar in natura apresentou pequena variação no $\mathrm{pH}$ durante as 9 horas de estudo (0,11 unidades), entretanto, a aplicação da cal hidratada implicou maior variação $(0,77$ e 0,51 unidades para cana hidrolisada com 0,5 e $0,6 \%$, respectivamente).

Independente da dose utilizada na hidrólise da cana-de-açúcar, verificou-se decréscimo nos valores de $\mathrm{pH}$ com o decorrer das horas (Figura 2).

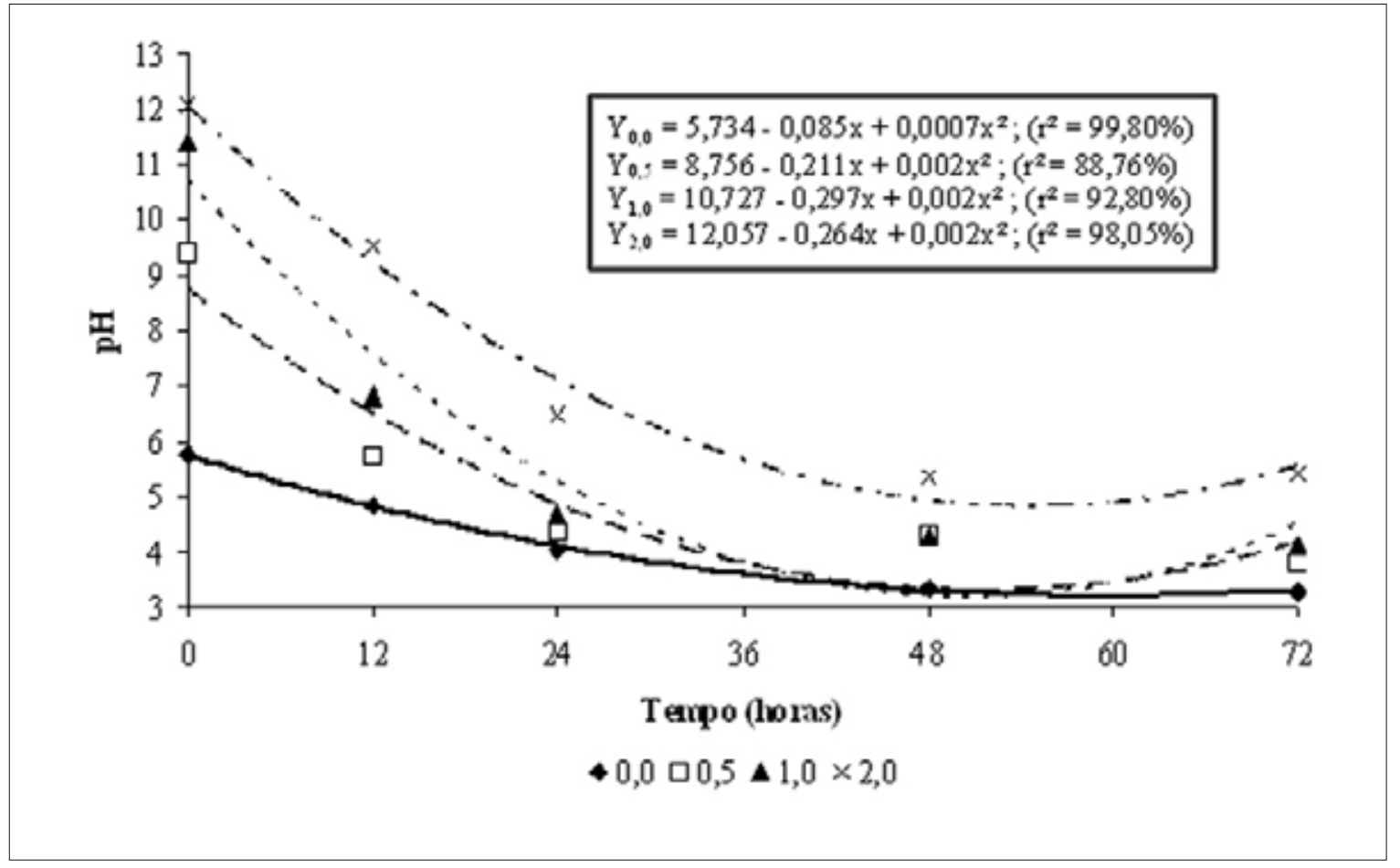

Figura 2 - Desdobramento da interação entre dose de cal virgem e tempo de repouso para valores de $\mathrm{pH}$. 
Os maiores valores de $\mathrm{pH}$ foram obtidos logo no momento da mistura "cana-cal", independente da dose utilizada, o que se deve à reação alcalina ocorrida no momento da hidrólise (Tabela 1).

Tabela 1 - Parâmetros de avaliação de pH (máximo valor, horas para atingir o máximo valor e $\mathrm{pH}$ acumulado) em função dos tratamentos aplicados à cana-de-açúcar

\begin{tabular}{lcccc}
\hline Tratamento & $\begin{array}{c}\mathrm{pH} \\
\text { máximo }\end{array}$ & $\begin{array}{c}\text { horas pH } \\
\text { máximo }\end{array}$ & $\begin{array}{c}\mathrm{pH} \\
\text { acumulado }\end{array}$ & $\mathrm{CV}(\%)$ \\
\hline controle & 5,73 & 0 & 21,23 & 3,38 \\
$0,5 \% \mathrm{CaO}$ & 8,75 & 0 & 27,62 & 6,12 \\
$1,0 \% \mathrm{CaO}$ & 10,72 & 0 & 31,27 & 4,55 \\
$2,0 \% \mathrm{CaO}$ & 12,05 & 0 & 38,86 & 3,93 \\
\hline
\end{tabular}

$\mathrm{O}$ maior valor de $\mathrm{pH}$ observado para a massa tratada com $2,0 \%$ de cal é decorrente da natureza alcalina do aditivo, como já explicado anteriormente. Da mesma forma, notou-se que com o aumento das doses de cal o $\mathrm{pH}$ acumulado aumentou também, devido aos maiores valores de $\mathrm{pH}$ terem sido obtidos com a hidrólise da cana-deaçúcar a 2,0\%, independentemente do tempo avaliado. Esse fato está associado à concentração de óxido de cálcio presente na cal; contudo, o fator preponderante para que isso ocorra é a dosagem utilizada na hidrólise. Os resultados verificados nesta pesquisa corroboram OLIVEIRA et al. (2008b), que observaram maiores valores de $\mathrm{pH}$ quando se utilizou a maior dose de cal $(1,0 \%$ com base na matéria verde).

A temperatura das massas não foi influenciada pelas doses de cal estudadas ( $\mathrm{P}>0,05)$; entretanto, houve efeito do tempo em aerobiose sobre essa variável $(\mathrm{P}<0,01)$. As médias observadas para o tratamento controle (in natura) e massas hidrolisadas com 0,$5 ; 1,0$ e $2,0 \%$ de cal foram, respectivamente, 32,$30 ; 31,80 ; 32,35$ e $31,55^{\circ} \mathrm{C}$.

De maneira geral, verificou-se que a temperatura no decorrer do tempo apresentou comportamento quadrático $(\mathrm{Y}=23,216+0,630 \mathrm{x}$ $\left.0,006 \mathrm{x}^{2} ; \mathrm{r}^{2}=80,60 \%\right)$. No momento da mistura "cana-cal" a temperatura aferida foi $23,21^{\circ} \mathrm{C}$, enquanto que, nos tempos 12, 24, 48 e 72 horas após, as temperaturas foram, respectivamente, 29,$91 ; 34,88 ; 39,63$ e $37,47^{\circ} \mathrm{C}$. Nota-se que houve acréscimo da temperatura até 48 horas e, a partir deste momento observou-se tendência de estabilização e queda, o que possivelmente pode ser explicado pela ação de microrganismos, os quais teoricamente consumiram os carboidratos solúveis, provocando reações que elevaram a temperatura e, quando a ação desses microrganismos estabilizouse, houve queda da temperatura até entrar em equilíbrio com a temperatura ambiente. $\mathrm{O}$ incremento de temperatura da forragem em aerobiose, decorrente da respiração da planta e/ou do crescimento de microrganismos aeróbicos, envolve utilização de nutrientes solúveis como fonte de energia, resultando em perda de nutrientes (WOOLFORD, 1978).

Ao estudar o efeito da interação entre dose e tempo $(\mathrm{P}<0,05)$, notou-se que todas as massas apresentaram comportamento quadrático em função do tempo de repouso, com temperatura máxima por volta de 48 horas, com exceção da massa tratada com $2,0 \%$ de cal virgem, que apresentou máxima temperatura após 72 horas (Figura 3).

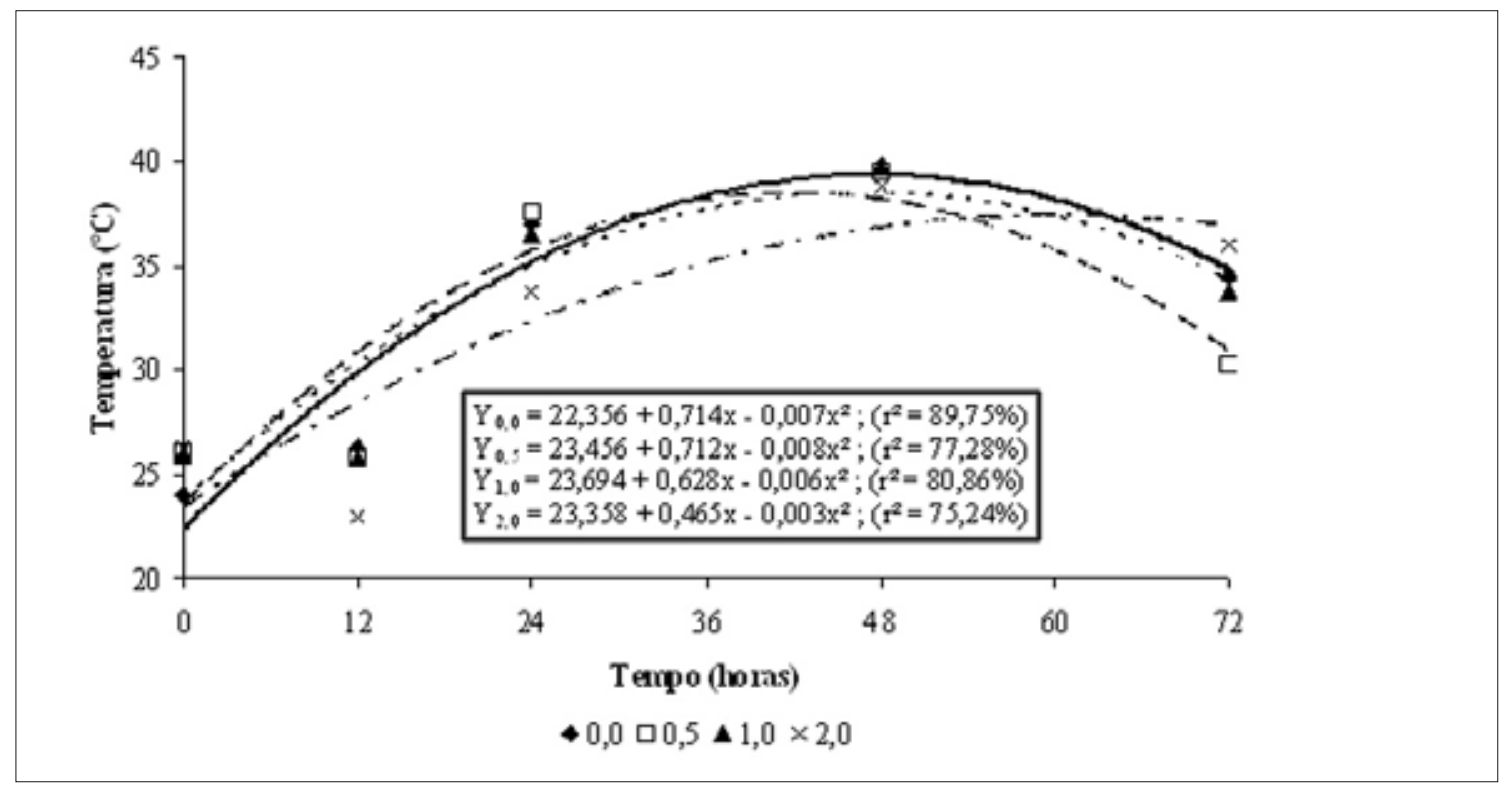

Figura 3 - Desdobramento da interação entre dose de cal virgem e tempo de repouso para temperatura $\left({ }^{\circ} \mathrm{C}\right)$. 
Quando se utilizou 2,0\% de cal virgem na hidrólise da cana-de-açúcar foi obtido o menor valor de temperatura acumulada (Tabela 2); no entanto, ao adicionar $1,0 \%$ de cal notou-se maior acréscimo na temperatura. A atividade de água corresponde ao percentual de água livre disponível ao crescimento de microrganismos GREENHILL (1964) e, desta forma, a aplicação de materiais com alto teor de matéria seca reduz a atividade de água na forragem (BALSALOBRE et al., 2001), dificultando o desenvolvimento de microrganismos espoliadores e por consequência diminui a produção de calor ao longo do período de exposição aeróbia.

Tabela 2 - Estabilidade aeróbia de cana-de-açúcar in natura em função das temperaturas aferidas

\begin{tabular}{lccccc}
\hline & $\begin{array}{c}\mathrm{t}^{\circ} \mathrm{C} \\
\text { Tratamento }\end{array}$ & haras & \multicolumn{2}{c}{ horas } & $\mathrm{t}^{\circ} \mathrm{C}$ \\
& $\mathrm{t}^{\circ} \mathrm{C}^{1}$ & $\mathrm{TA}^{2}$ & $\mathrm{t}^{\circ} \mathrm{C}>2^{\circ} \mathrm{C}^{3}$ & acumulada \\
\hline controle & 40,56 & 51 & 0,79 & 0 & 161,48 \\
$0,5 \% \mathrm{CaO}$ & 39,29 & 44 & 0,89 & 0 & 158,97 \\
$1,0 \% \mathrm{CaO}$ & 40,12 & 53 & 0,75 & 0 & 161,72 \\
$2,0 \% \mathrm{CaO}$ & 41,28 & 72 & 0,57 & 0 & 157,72 \\
\hline
\end{tabular}

A cana-de-açúcar in natura apresentou maior temperatura após 51 horas de exposição aeróbia, já para as massas hidrolisadas com 0,5 e $1,0 \%$ de cal, notaram-se maiores temperaturas após 44 e 53 horas do momento da mistura "cana-cal", respectivamente. A hidrólise da cana-de-açúcar $2,0 \%$ retardou a temperatura máxima, observada após 72 horas. Com base no somatório das temperaturas nos três dias de avaliação, notou-se que as doses de 0,5 e 2,0\% foram mais eficazes em controlar a temperatura (Tabela 2), o que possibilita inferir que essas doses inibiram o crescimento de microrganismos. Segundo MCDONALD et al. (1991), em condições aeróbicas as leveduras crescem muito rapidamente e produzem energia através da glicose pela via da glicólise e do ciclo do ácido tricarboxilíco. A completa oxidação dos açúcares pelas leveduras forma dióxido de carbono e água.

A menor taxa de aquecimento (temperatura máxima dividida pelo tempo necessário para atingila) foi verificada nas massas tratadas com $2,0 \%$ de cal $(0,57)$, fato que se deve à maior quantidade de aditivo aplicado à cana-de-açúcar, já que a cal utilizada no presente trabalho apresentou baixa concentração de óxido de cálcio $(64,0 \%)$, requerendo maior quantidade para que ocorresse a devida hidrólise do material. A cana-de-açúcar tratada com $0,5 \%$ de cal provocou maior aquecimento da cana-de-açúcar (Tabela 2).

Todas as massas apresentaram mais de $2^{\circ} \mathrm{C}$ acima da temperatura ambiente logo no momento da mistura "cana-cal" (tempo 0), o que pode ser explicado pelo momento da mistura ter ocorrido à noite (23:00 horas), quando as temperaturas eram baixas e, com efeito, quando se adiciona cal virgem à cana-de-açúcar, a reação hidrolítica promove aquecimento das massas. Devido a isso, não se pode considerar que as massas de cana-de-açúcar apresentaram deterioração logo no momento da mistura (Figura 4).

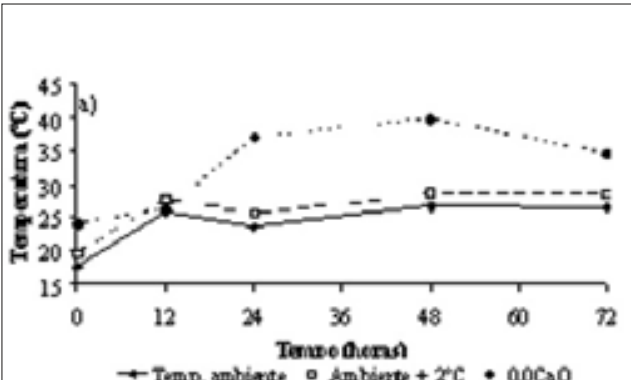

- Temp ambiate o Ambiente $+2 \mathrm{C} \cdot 0,0 \mathrm{CaO}$

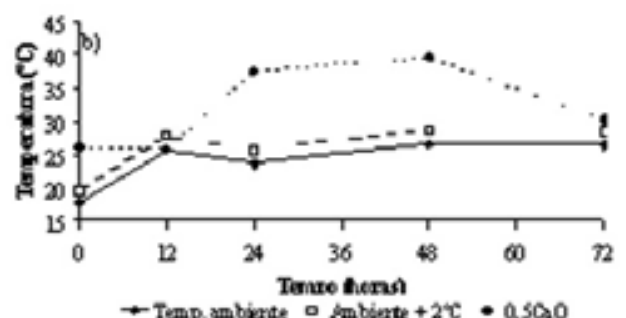

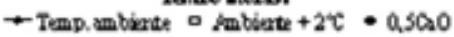

Figura 4 - Quebra da estabilidade aeróbia da cana-de-açúcar natura $(0,0 \%$ de cal) (a) e hidrolisada com $0,5 \%$ (b) $1,0 \%$ (c) e $2,0 \%$ de cal (d) em função da temperatura ambiente ao longo do período avaliado.

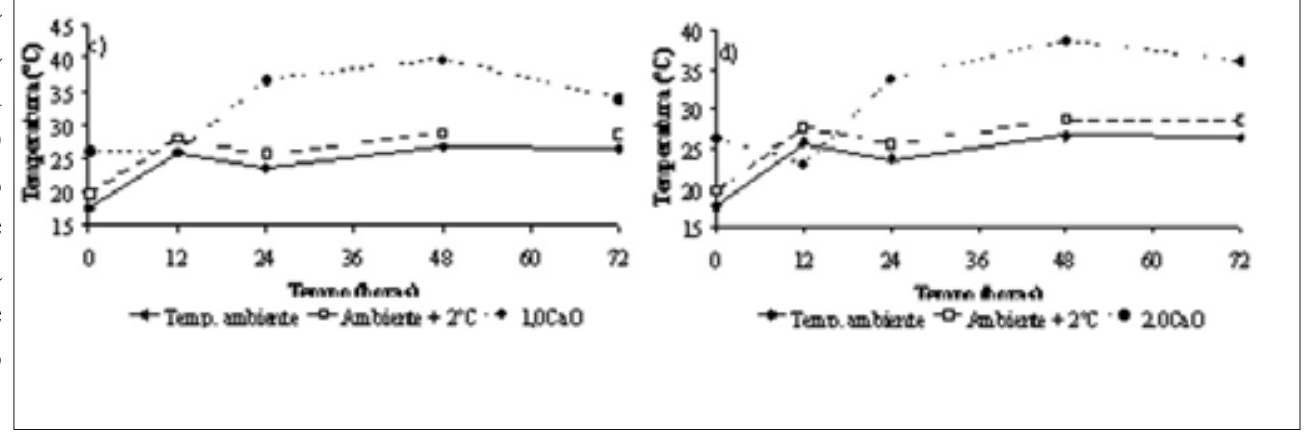


A cana-de-açúcar que permaneceu in natura apresentou quebra da estabilidade aeróbia após 13 horas do momento da mistura, a massa tratada com $0,5 \%$ de cal, apresentou estabilidade até 14 horas, o mesmo observado para a massa tratada com $1,0 \%$ de cal, e por último, a massa tratada com $2,0 \%$ de cal apresentou estabilidade aeróbia até 16 horas após o momento inicial da hidrólise. Conforme descrito por AMARAL et al. (2009), essa quebra de estabilidade aeróbia antecipada da cana-de-açúcar in natura era previsível, pois a maior concentração de carboidratos solúveis na forragem provavelmente possibilita maior reprodução de microrganismos (entre eles, leveduras e fungos filamentosos), possibilitando maior atividade destes e, por conseguinte, quebra da estabilidade aeróbia.

O fato de a hidrólise ter proporcionado 3 horas a mais de estabilidade aeróbia $(2,0 \%$ de cal virgem) está associado ao maior "tempo de cocho" da cana-de-açúcar, consequentemente, o alimento poderá ser fornecido em maiores quantidades por refeição, porém em menor frequência, reduzindo desta forma custos operacionais envolvendo mão-de-obra. Contudo, esse acréscimo na estabilidade aeróbia pode ser potencializado utilizando-se cales com teor de óxido de cálcio mais elevado comparativamente a este estudo, em que se utilizou a cal com $64 \%$ de $\mathrm{CaO}$.

Os tempos de estabilidade aeróbia encontrados nesta pesquisa foram inferiores ao encontrado por AMARAL et al. (2009), que observaram que a quebra de estabilidade aeróbia da cana-de-açúcar in natura ocorreu após 33,7 horas de exposição ao ar. RIBEIRO et al. (2009) verificaram maior estabilidade da cana-de-açúcar quando tratada com cal virgem, independente da dose utilizada, quando comparado ao tratamento controle.

\section{CONCLUSÕES}

A inclusão de $2,0 \%$ de cal virgem aumenta a estabilidade aeróbia da cana-de-açúcar e proporciona menor taxa de aquecimento. Entretanto, há a necessidade da aplicação de doses elevadas para que ocorra adequado processo hidrolítico da forragem em virtude do baixo teor de óxido de cálcio presente na cal.

\section{REFERÊNCIAS}

AMARAL, R.C.; PIRES, A.V.; SUSIN, I.; NUSSIO, L.G.; FERREIRA, E.M.; GENTIL, R.S. Cana-de-açúcar in natura ou ensilada com e sem aditivos químicos: estabilidade aeróbia dos volumosos e das rações. Revista Brasileira de Zootecnia, v. 38, n. 10, p. 1857-1864, 2009.

ASSOCIATION OF OFFICIAL ANALYTICAL CHEMISTS. Official methods of analysis. 11.ed. Washington, DC, 1970. $1015 \mathrm{p}$.

BALIEIRO NETO, G.; FERRARI JR., E.; NOGUEIRA, J.R.; POSSENTI, R.; PAULINO, V.T.; BUENO, M.S. Perdas fermentativas, composição química, estabilidade aeróbia e digestibilidade aparente de silagem de cana-deaçúcar com aditivos químico e microbiano. Pesquisa Agropecuária Brasileira, Brasíla, v. 44, n. 6, p. 621-630, 2009.

BALSALOBRE, M.A.A.; NUSSIO, L.G.; MARTHA JR., G.B. Controle de perdas na produção de silagens de gramíneas tropicais. In: MATTOS, W.R.S.; FARIA. V.P.; DA SILVA, S.C. (Eds.). A produção animal na visão dos brasileiros. Piracicaba: Fundação de Estudos Agrários "Luiz de Queiroz", 2001. p. 890-911.

CHERNEY, J.H.; CHERNEY, D.J.R. Assessing Silage Quality. In: BUXTON, D.R.; MUCK, R.; HARRISON, J. (Eds.). Silage Science and Technology. Madison: American Society of Agronomy, 2003. p. 141-198.

EZEQUIEL, J.M.B.; QUEIRÓZ, M.A.A.; GALATI, R.L. Processamento da cana-de-açúcar: Efeito sobre a digestibilidade, o consumo e a taxa de passagem. Revista da Sociedade Brasileira de Zootecnia, Viçosa, v. 34, n. 5, p. 1704-1710, 2005.

FERREIRA, D.F. SISVAR: um programa para análises e ensino de estatística. Revista Científica Symposium, Lavras, v. 6, p. 36-41, 2008.

GREENHILL, W.L. Plant juice in relation to silage fermentation. Journal of the British Grassland Society, Oxford, v. 19, p. 336-339, 1964.

KLOPFENSTEIN, T. Increasing the nutritive value of crop residues by chemical treatments. In: HUBER, J.T. Upgrading residues and products for animals. Ed. CRC Press, 1980, p. 40-60.

MCDONALD, P.; HENDERSON, A.R.; HERON, S.J.E. The biochemistry of silage. 2.ed. Marlow: Chalomb $\mathrm{Pu}$ blications, 1991. $340 \mathrm{p}$.

NUSSIO, L.G.; SUSIN, I.; MENDES, C.Q.; AMARAL, R.C. Estratégias para garantir eficiência na utilização de cana-de-açúcar para ruminantes. Tecnologia \& Ciência Agropecuária, João Pessoa, v. 3, n. 4, p. 27-33, 2009.

OLIVEIRA, M.D.S.; SANTOS, J.; DOMINGUES, F.N.; LOPES, A.D.; SILVA, T.M.; MOTA, D.A.; Avaliação da 
cal hidratada como agente hidrolisante de cana-de-açúcar. Veterinária Notícias, Uberlândia, v. 14, n. 1, p. 9-17, 2008a.

OLIVEIRA, M.D.S.; BARBOSA, J.C.; MOTA, D.A.; ANDRADE, A.T. Efeito da hidrólise com cal virgem sobre a composição bromatológica da cana-de-açúcar. Veterinária Notícias, Uberlândia, v. 14, n. 1, p. 9-17, 2008 b.

PEDROSO, A.F.; NUSSIO, L.G.; LOURES, D.R.S.; PAZIANI, S.F.; IGARASI, M.S.; COELHO, R.M.; HORII, J.; RODRIGUES, A.A. Efeito do tratamento com aditivos químicos e inoculantes bacterianos nas perdas e na qualidade de silagens de cana-de-açúcar. Revista Brasileira de Zootecnia, Viçosa, v. 36, n. 3, p. 558-564, 2007.

RANJIT, N.K.; KUNG JR., L. The effect of Lactobacillus buchneri, Lactobacillus plantarum, or chemical preservative on the fermentation and anaerobic stability of corn silage. Journal of Dairy Science, Savoy, v. 83, p. 526-535, 2000 .

RIBEIRO, L.S.O.; PIRES, A.J.V.; PINHO, B.D.; CARVALHO, G.G.P., FREIRE, M.A.L. Valor nutritivo da cana-de-açúcar hidrolisada com hidróxido de sódio ou óxido de cálcio. Arquivo Brasileiro de Medicina Veterinária e Zootecnia, Belo Horizonte, v. 61, n. 5, p. 11561164, 2009.

RUPPEL, K.A.; PITT, R.E.; CHASE, L.E. Bunker silo management and its relationship to forage preservation on dairy farms. Journal of Dairy Science, Savoy, v. 78, n. 1, p. 141-153, 1995.

SILVA, D.J. Análise de alimentos: métodos químicos e biológicos. Viçosa: UFV, Impr. Univ., 1981. 166 p.

SILVA, D.J.; QUEIROZ, A.C. Análise de alimentos: métodos químicos e biológicos. 3.ed. Viçosa: UFV, 2002. $235 \mathrm{p}$.

SIQUEIRA, G.R.; BERNARDES, T.F.; REIS, R.A. Instabilidade aeróbia de silagens: efeitos e possibilidades de prevenção. In: REIS, R.A.; SIQUEIRA, G.R.; BERTIPAGLIA, L.M.A.; OLIVEIRA, A.P.; MELO, G.M.P.; BERNARDES, T.F. (Eds.). Volumosos na Produção de Ruminantes. Jaboticabal: FUNEP, 2005. p. 25-60.

WOOLFORD, M.K. The problem of silage effluent. Herbage Abstracts, Wallingford, v. 48, p. 397-403, 1978.

Protocolado em: 22 dez. 2009. Aceito em: 18 fev. 2011. 